\title{
Revendo as relações entre \\ ciência, Estado e sociedade: \\ a perspectiva sócio-histórica da estatística
}

(PRÉVOST, Jean-Guy; BEAUD, Jean-Pierre. Statistics, public debate and the State, 18001945: a social, political and intellectual history of numbers. London: Pickering and Chatto, 2012, 235 p.)

Alexandre de Paiva Rio Camargo*

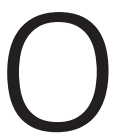
leitor está diante de uma obra madura, resultado de sólida e longeva parceria intelectual entre os autores, que há 25 anos têm se dedicado à política dos números e à sócio-história da estatística. Não por acaso, o livro em tela consiste na revisão e ampliação de oito artigos publicados entre 1997 e 2009 em prestigiosos periódicos canadenses, americanos e franceses, acrescidos de uma esclarecedora introdução que dá unidade e fio condutor à leitura.

Nesta extensa trajetória, cumpre destacar a realização, em setembro de 1999, de um ciclo de conferências em sua instituição de origem, a Université du Québec, em Montreal, que deu origem ao livro L'ère du chiffre: systèmes statistiques et traditions nationales (Beaud e Prévost, 2000). Na ocasião, os autores coordenaram os trabaIhos de nomes como lan Hacking, Alain Desrosières e Theodore Porter para oferecer uma primeira proposta de reflexão comparativa das relações entre, de um lado, a difusão do internacionalismo estatístico, com a normalização das classificações, dos instrumentos de mensuração, e da infraestrutura de contagem populacional, e, de outro, a conformação histórica das práticas estatísticas nacionais, cujo perfil é inseparável da genealogia dos Estados, das culturas políticas e das estruturas locais de dominação. É por esta relação essencial, que funda e norteia a inteligibilidade social e a produtividade política das estatísticas públicas, que se verificam as profundas diferenças nacionais de institucionalidade na produção dos dados, de participação das comunidades especializadas na configuração da ação pública, e de emprego de tecnologias de visualização/objetivação do povo e do território, assinaladas por uma hoje já expressiva bibliografia.

Statistics, public debate and the State (1800-1945) prossegue nesta seara inaugurada por L'ère du chiffre, em particular acerca da necessidade de superar-se o nacionalismo metodológico como grade para o estudo deste objeto-fronteira que é a estatística.

\author{
* Doutorando \\ em sociologia \\ pelo Instituto de \\ Estudos Sociais \\ e Políticos (lesp) \\ da Universidade \\ do Estado do Rio \\ de Janeiro (Uerj). \\ Mestre e bacharel \\ em história pela \\ Universidade \\ Federal Fluminense \\ (UFF). Integrante \\ do Sociofilo, \\ núcleo de pesquisa \\ sobre filosofia das \\ ciências sociais, \\ dirigido por Frédéric \\ Vandenberghe. \\ Coorganizador, \\ junto a Nelson de \\ Castro Senra, do \\ livro Estatísticas \\ nas Américas: por \\ uma agenda de \\ estudos históricos \\ comparados (Rio \\ de Janeiro, IBGE, \\ 2010). Bolsista da \\ Coordenação de \\ Aperfeiçoamento \\ de Pessoal de \\ Nível Superior \\ (Capes). <alexandre. \\ camargo.2009@ \\ gmail.com>.
}


Isto porque - como lembram os autores - ela se encontra na injunção entre os universos da ciência, que Ihe confere uma pretendida legitimidade superior; o da administração pública, que lhe delimita e imprime orientação; o da política, que lhe converte em referente normativo para a mediação de conflitos. Vista em seus três polos constituintes, a estatística não deve ser tomada a partir de seus próprios termos técnicos de redução do erro e de aproximação à realidade preexistente, mas antes - defendem os autores -, concebida como espaço político-cognitivo a partir do qual demandas e problemas políticos tornam-se objeto de constante conversão e tradução técnica, possibilitando novas formas de apresentar, discutir, gerir e resolver aquelas questões (p. 3).

Como este espaço político-cognitivo se forma e se transforma historicamente é a preocupação central de Beaud e Prévost, que nos oferecem neste livro um passeio por diferentes configurações espaço-temporais das relações intrínsecas entre estatística, Estado e esfera pública, entre 1800 e 1945.

Sem se deparar com qualquer pretensão de exaustividade, o leitor encontrará temas diversos, que vão dos primeiros (e hesitantes) usos da percentagem na lenta construção de uma linguagem de objetividade e intervenção (séculos XVIII e XIX) à revolução política e epistemológica representada pela adoção da amostragem probabilística nas estatísticas oficiais, através da qual se realizou a montagem da engenharia institucional do Estado social, na primeira metade do século XX. O recorte espacial é igualmente variado: dos inquéritos estatísticos como melhoramento da empresa colonial, no Canadá do início do século XIX, ao nacionalismo estatístico da Itália liberal e fascista; das fracassadas tentativas de centralização das estatísticas imperiais, na Inglaterra vitoriana, à controvérsia estatística nos Estados Unidos sobre o papel da imigração no crescimento populacional; da realização dos primeiros censos modernos à mundialização dos sistemas estatísticos nacionais.

Para efeito expositivo, dividimos o argumento da publicação em dois eixos. No primeiro, situamos o lugar da estatística na construção dos debates públicos, colocando em evidência e discussão os acordos sobre o que pode (e, por exclusão, o que não pode) ser definido, classificado, contado e quantificado em um dado momento histórico, e, portanto, convencionado em matéria de posição e papel dentro de um espaço de equivalências, fundamento das necessárias e desejadas comparações.

Neste sentido, é muito interessante o Capítulo II (p. 27-48), que parte das monografias realizadas no Canadá do início do XIX para analisar a continuidade entre os levantamentos de população e os procedimentos de petição parlamentar. Através do estudo das iniciativas "amadoras" de Robert Gourlay, vemos que a estatística é aqui usada e pensada como instrumento de consulta aos súditos da coroa inglesa, inquiridos sobre as condições de vida que deveriam ser melhoradas durante verda- 
deiras audiências públicas. No momento em que o prestígio dos depoimentos de clero e nobreza começava a cair em desuso como fonte de verdade, acompanhamos na prática estatística de Gourlay um novo sentido de sistematicidade, autenticidade e publicidade da informação, afeita à "epistemologia democrática" que caracteriza o nascimento da esfera pública.

Outros dois capítulos privilegiam a construção estatística de objetos e representações em debates públicos, agora já no contexto de consolidação das agências estatísticas nacionais e de passagem da estatística descritiva e literária para a estatística matemática, movimento que acompanha a diversificação das comunidades profissionais que disputam o monopólio de interpretação legítima dos dados. Esta passagem está bastante presente no Capítulo V (p. 91-110), que traz para o centro uma das principais controvérsias estatísticas já ocorridas nos Estados Unidos: a teoria sobre o suposto efeito nulo da imigração em relação ao crescimento populacional, elaborada por Francis Walker, em 1891.

Ao se basear na exatidão aproximada das previsões de população feitas em 1790 e 1800 para o ano de 1815, quando a imigração ainda não era a variável significativa da composição demográfica, na comparação com a segunda metade do século XIX, Walker postula o impacto negativo da imigração como freio do crescimento nativo. Nesta visão, a imigração não passaria de substituição do crescimento vegetativo da população pelo estoque estrangeiro. Por um lado, o capítulo explora a imediata acolhida do argumento entre os partidários de atitudes nativistas e de restrição à imigração, que teve na política das cotas um dos subprodutos diretos da publicação da tese. Por outro lado, analisa como o meio acadêmico cerrou posições diante da hegemonia da teoria, em uma polarização de mais de 20 anos. Beaud e Prévost descortinam o momento de transição representado pelo extenso debate, no qual fica cada vez mais patente a dificuldade dos defensores em disfarçar tecnicamente o caráter político de suas predileções nativistas e racistas, diante dos novos procedimentos de prova e rigor científico que pautariam as intervenções mais tardias como, por exemplo, o desenvolvimento de atitude crítica em relação às fontes, incluindo a estimativa do grau de confiabilidade dos censos, intensamente invocados pelos dois lados do debate; o estabelecimento da taxa de fertilidade (uma variável fundamental) por processos de tentativa e erro; além do tratamento matemático das correlações, limitando inferências mais intuitivas. Ao final, o triunfo dos críticos, mais próximos de estatísticos profissionais e cientistas da população, aponta para a nova organização universitária da pesquisa demográfica e a constituição da demografia como disciplina científica, nos anos 1910 e 1920.

São exatamente estes os anos enfocados pelo Capítulo VII (p. 133-152), dedicado à formação da expertise estatística nos estertores da Itália liberal. Se o caso norte-americano ilustra o fechamento dos debates estatísticos pela restrição dos que nele podem 
participar, a experiência italiana nos mostra o engajamento nacionalista pelas sofisticadas traduções técnicas de uma emergente comunidade profissional de estatísticos.

Somos levados a compreender um determinado padrão de intervenção pública que atravessa as manifestações do grupo, a despeito de suas expressivas diferenças internas, iniciando pelas contribuições de Conrado Gini, em 1918, concernentes ao custo da guerra para a Itália. Nelas, o líder de escola diminui a importância das perdas inevitáveis para o país, como o endividamento externo e os danos de guerra, pelo cálculo dos ganhos esperados pela vitória, caso da riqueza decorrente da incorporação de novos territórios, o crescimento de alguns setores industriais e a obtenção de reparações de guerra. Pela comparação com seus cálculos anteriores sobre a riqueza nacional em 1914, a projeção para 1918, nas duas hipóteses de inocorrência do conflito e de vitória italiana junto aos aliados, torna-se extremamente desfavorável, ajudando a formar a imagem de "vitória mutilada", que iria ganhar a retórica política com a ascensão de Mussolini. A mesma imagem é traduzida em outros estudos, como os de Giorgio Mortara sobre o impacto das mortes de civis e militares na economia dos países aliados, mais sensível no caso italiano, e os de Ugo Giusti e Franco Savorgnan, sobre a superioridade numérica e étnica dos italianos nos territórios disputados com a Áustria e a nascente lugoslávia. Prévost mostra como, em seu conjunto, os artigos ofereceram fundamento técnico às reivindicações políticas italianas. O êxito do trabaIho de representação dos estatísticos na construção da imagem de "vitória mutilada" é o argumento central do artigo, e pode ser medido por sua participação na comissão americana encarregada de avaliar o financiamento da dívida italiana, em 1925. Segundo o autor, a decisão favorável não só garantiu a estabilização política e econômica do governo de Mussolini como deslanchou o investimento do fascismo na reorganização das estatísticas oficiais, com a criação do Istituto Centrale di Statistica (Istat), em 1926, sinalizando para uma adesão tácita e produtiva dos estatísticos na construção do regime, tema de outra publicação recente do autor (Prévost, 2009).

O eixo que abrange os Capítulos III, IV, VI e VIII concentra-se nas instituições estatísticas e relações mútuas entre as metamorfoses do Estado e a estruturação dos apareIhos de contagem, incluindo a divisão do trabalho estatístico. O livro, em especial no seu Capítulo IV, aborda em panorama as condições que presidem o novo contexto de regularização da produção de dados e que se confundem com a descoberta do social e a invenção da moderna máquina administrativa.

Pelas sessões dos congressos internacionais de estatística - iniciados em 1853 por idealização e presidência de Adolph Quetelet, cuja trajetória é tema de um capítulo (p. 49-61) - debatiam-se as questões fundamentais da produção censitária: normalização das classificações, precisão na definição das categorias, clareza dos questionários e procedimentos que convinham à sua aplicação. Igualmente, importava conven- 
cer os governos a criarem as agências nacionais de estatística e, nesse sentido, fixar as atribuições dos produtores e das autoridades públicas, definindo uma engenharia que permitisse o repasse ministerial dos registros administrativos e eliminasse a duplicação das contagens, sem acentuar as tensões decorrentes da concorrência burocrática. Esta é a discussão do Capítulo IV (p. 63-89), que parte da realização dos primeiros censos modernos e da criação das primeiras agências de produção de dados em diversos países entre 1800 e 1850, para analisar o modelo organizacional dos sistemas estatísticos nacionais. Os autores examinam atentamente como o debate que opõe a centralização e a descentralização da produção dos dados oficiais se constituiu na principal plataforma ideológica da militância dos estatísticos, pelo menos até 1945. O argumento se divide entre a dissecação do raciocínio empregado pelos estatísticos administradores em prol dos méritos da centralização e as condições de resistência à criação de agências centrais de coordenação estatística nos países de forte tradição liberal e cultura de informação, caso notável dos Estados Unidos e da Inglaterra, que só muito tardiamente consentiram em criar o Bureau of Census (1902) e o Central Statistical Office (1940). A este respeito, o Capítulo VI (p. 111-131) fornece um ilustrativo complemento, trazendo como tema a fracassada tentativa de criação de uma agência de coordenação das estatísticas do Império Britânico. O texto também é interessante por revelar a inspiração bourdieusiana seguida pelos autores, mais clara aqui do que em outros capítulos da publicação.

A adoção da amostragem probabilística, é estudada em "The politics of sampling revolution" (p. 153-172), talvez o mais original dos capítulos da publicação. Ao criticarem a historiografia internalista que aborda a amostragem representativa como mero avanço técnico explicado em termos de racionalidade econômica, isto é, redução de custos da pesquisa e disponibilização mais rápida dos seus resultados, Prévost e Beaud insistem, de forma provocativa e convincente, que há muito mais do que uma querela metodológica no extenso debate que termina com a aceitação imediata do famoso trabalho de Jerzy Neyman sobre a amostragem estratificada aleatória em 1934, e sua introdução pioneira na produção de estatísticas oficiais, realizada na pesquisa de desemprego do Census Bureau americano, em 1936, pelas mãos de Morris Hansen e Edwards Deming. Remontando a 1895, com o experimento do norueguês Anders Kiaer, os autores reconstroem as controvérsias havidas no International Statistical Institute, apontando para o equívoco de se opor as noções de exaustividade e exatidão subjacentes ao modelo censitário às de aproximação e precisão implícitas na amostragem.

Se quisermos compreender como se tornou possível a revolução político-cognitiva promovida pela amostragem probabilística, ensinam os autores, precisamos buscar, ao contrário, as continuidades que ligam estas duas formas de representação estatística. Assim, é possível entender porque a amostragem proposital (purposive sampling) dominava todas as defesas do método, até os anos 1930. A aleatoriedade não era 
uma possibilidade para nenhum dos lados do debate, precisamente porque a amostragem era pensada a partir das mesmas categorias cognitivas do realismo censitário, isto é, nos termos da tipicidade. Uma cidade ou região consideradas típicas eram então vistas como a média das cidades e regiões de um dado conjunto, o que perfazia a ideia do tipo por referência à média, em contraste com o acidental e o excepcional. Isto quer dizer que, se o tipo pode existir como conjunto abstrato de características comuns a todos os subconjuntos, cada um destes, por sua vez, resulta bastante concreto e real, inseparáveis da consistência orgânica do todo. Deste modo, ficava implícita na amostragem proposital a vinculação realista e territorial da representatividade, a mesma que caracteriza a contagem censitária, fundada na divisão do território em distritos e no reconhecimento de seu fracionamento interno:

\begin{abstract}
A possibilidade dos distritos censitários já definidos ou outras subunidades políticas serem uma amostra adequada de todo o país se enquadra bem com esta demarcação espacial - ou seja, a ideia de que pequenos territórios possam ser equivalentes a um grande território não parece ridícula nesse raciocínio, muito menos se algumas variáveis de fato correlacionam (p. 162).
\end{abstract}

O problema, porém, é que o experimento de Gini, realizado em 1925, demonstrou que a amostragem proposital não garantia a correlação de um número estatisticamente interessante de variáveis. Tudo apontava para a dissolução do debate, com a proscrição da amostragem.

Sendo assim, fica a questão que mais intriga o leitor: sob que condições a amostragem aleatória, que se refere a uma realidade de segunda ordem, atomística, formada por uma coleção de unidades desterritorializadas, acaba se afirmando como uma possibilidade (quase) impositiva? Seguindo os passos de Alain Desrosières (1988: 93-112), os autores argumentam que a substituição legítima do todo pela parte só poderia emergir quando as técnicas locais de administração dos problemas sociais, compatíveis com os governos cuja função não vai muito além de oferecer aos agentes econômicos um conhecimento muito geral das condições em que operam, cedem lugar ao gerenciamento de um governo nacional em vias de se tornar um Estado social. A nova concepção de precisão que aparecem com as técnicas de amostragem faria mais sentido para um governo que concebe a produção de dados pelo grau de significação que eles podem imprimir à sua ação. Nos Estados Unidos do New Deal, a amostragem aparecerá como procedimento eficaz de retratar, de forma precisa, atualizada e contínua as transformações da realidade econômica, a serem refreadas ou aceleradas por medidas orçamentárias e fiscais (p. 170).

A extensão dos temas e recortes deste livro obrigou-nos a alongar sua resenha, para não perdermos a densidade de sua contribuição à historiografia da estatística. Parece- 
-nos sintomático que Jean-Pierre Beaud e Jean-Guy Prévost tenham ajudado a criar a Associação das Américas para a História da Estatística e do Cálculo de Probabilidades (AAHECP), que tem naquele o seu primeiro presidente. São dois estudiosos que há muito têm levado a pesquisa comparativa a horizontes antes impensados nessa área. Cabe, agora, estendê-la para abranger também os países da América Latina, que não protagonizaram debates como os que foram aqui apresentados, mas que os receberam de forma criativa e original.

Afora os méritos que fazem de Statistics, public debate and the State atraente para todos aqueles interessados nas relações entre Estado e sociedade, entre política e ciência, da história à sociologia, da demografia à epistemologia, este livro se apresenta como peça indispensável na construção coletiva de uma agenda de estudos históricos comparados neste importante e emergente domínio. Aí reside, a nosso ver, o seu maior valor.

\section{Referências}

BEAUD, Jean-Pierre; PRÉVOST, Jean-Guy (Orgs.). L'ère du chiffre: systèmes statistiques et traditions nationales. Quebec: Presses de l'Université du Québec, 2000.

DESROSIÈRES, Alain. La partie pour le tout: comment généraliser? La préhistoire de la contrainte de répresentativité. Statystique et Analyse des Données, v. 13, n. 2. 1988, p. 93-112.

PrÉVOST, Jean-Guy. A total science: statistics in liberal and fascist italy. Montreal; Kingston: McGill-Queen's University Press, 2009. 